Artigo Original

\title{
Intervenções de enfermagem para náusea e vômito no período pós-operatório imediato*
}

\author{
Nursing interventions for the prevention and relief of nausea and vomiting during the immediate \\ postoperative period
}

Intervenciones de enfermería para náusea y vómito en el periodo postoperatorio inmediato

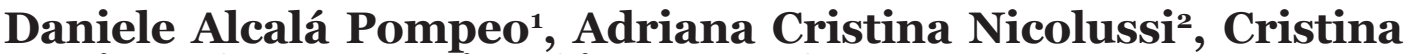 Maria Galvão ${ }^{3}$, Namie Okino Sawada ${ }^{3}$}

\begin{abstract}
RESUMO
Objetivo: analisar as evidências disponíveis na literatura sobre as intervenções de enfermagem eficazes para a prevenção e o controle da náusea e do vômito presentes, no paciente no período pós-operatório imediato. Métodos: revisão de literatura, a busca dos artigos foi realizada nas bases de dados Lilacs, Medline e Cinahl e na listagem das referências bibliográficas dos artigos selecionados, sendo a amostra constituída de 12 artigos. Resultados: no pré-operatório o enfermeiro identifica os fatores de risco e minimiza a ansiedade do paciente; no trans-operatório deve estar atento à cirurgia, duração, complicações, medicações e anestésicos administrados e, no pós-operatório, pode intervir por meio de medidas comportamentais e de conforto. Conclusão: as evidências obtidas demonstraram que há intervenções alternativas para a prevenção e o controle da náusea e do vômito no pós-operatório, não implementadas na prática clínica, as quais podem melhorar essas complicações e a satisfação do paciente.

Descritores: Náusea e vômito no pós-operatório/prevenção \& controle; Cuidados de enfermagem
\end{abstract}

\begin{abstract}
Objective: to determine the effectiveness of nursing interventions for the prevention and relief of nausea and vomiting during the immediate postoperative period. Methods: a literature search was conducted in Lilacs, Medline and Cinahl databases and in the reference list of selected articles. The final sample of this study consisted of 12 articles. Results: during the preoperative period, nurses identify risk factors for anxiety and provide nursing interventions to minimize them. During the intra-operative period, nurses pay attention to the surgical procedure, its duration and complications, and medications and anesthetic agents. During the postoperative period, nurses provide nursing interventions regarding behavioral and comfort measures. Conclusion: alternative interventions to prevent and control postoperative nausea and vomiting are not implemented in clinical practice. These alternative interventions might improve client satisfaction and prevent complications.
\end{abstract}

Keywords: Postoperative nausea and vomiting/prevention \& control; Nursing care

\section{RESUMEN}

Objetivo: analizar las evidencias disponibles en la literatura sobre las intervenciones de enfermería eficaces para la prevención y el control de la náusea y del vómito presentes, en el paciente en el período postoperatorio inmediato. Métodos: la revisión de la literatura, la búsqueda de los artículos fue realizada en las bases de datos Lilacs, Medline y Cinahl y en la lista de las referencias bibliográficas de los artículos seleccionados, estando constituida la muestra de 12 artículos. Resultados: en el pre-operatorio el enfermero identifica los factores de riesgo y minimiza la ansiedad del paciente; en el trans-operatorio debe estar atento a la cirugía, duración, complicaciones, medicaciones y anestésicos administrados y, en el postoperatorio, puede intervenir por medio de medidas de comportamiento y de confort. Conclusión: las evidencias obtenidas demostraron que hay intervenciones alternativas para la prevención y el control de la náusea y del vómito en el post-operatorio, no implementadas en la práctica clínica, las cuales pueden mejorar esas complicaciones y la satisfacción del paciente.

Descriptores: Náusea y vómito en el post-operatorio/prevención \& control; Cuidados de enfermería

\footnotetext{
* Trabalho final da Disciplina de Pós-Graduação Enfermagem Perioperatória Baseada em Evidências ministrada na Escola de Enfermagem - Univeriddade de São Paulo - USP - Ribeirão Preto, (SP), Brasil.

${ }^{1}$ Pós-graduanda do Programa de Pós-Graduação Enfermagem Fundamental da Escola de Enfermagem de Ribeirão Preto da Universidade de São Paulo - USP

- Ribeirão Preto (SP), Brasil.

2 Pós-graduanda do Programa de Pós-Graduação Enfermagem Fundamental da Escola de Enfermagem de Ribeirão Preto da Universidade de São Paulo - USP - Ribeirão Preto (SP), Brasil..

${ }^{3}$ Professor Associado do Departamento de Enfermagem Geral e Especializada da Escola de Enfermagem de Ribeirão Preto da Universidade de São Paulo USP - Ribeirão Preto (SP), Brasil. 


\section{INTRODUÇÃO}

Os cuidados que o doente necessita durante o período pós-operatório constituem um desafio devido às alterações fisiológicas complexas que ocorrem nesta fase. Uma das manifestações mais comuns em Sala de Recuperação Anestésica (SRA) é a náusea e o vômito, geralmente associados à anestesia. Em procedimentos anestésico-cirúrgicos destituídos de outras complicações, freqüentemente, o paciente terá como principal e desagradável lembrança a experiência deste evento, como relatado em um estudo que avaliou os aspectos negativos que o paciente gostaria de evitar na SRA. Náuseas e vômitos no pós-operatório (NVPO) foram os que maior número de pacientes desejaria evitar (49\%), seguido de outros, como a dor $(27 \%)$ e a ausência de sedação $(13 \%)$. Os autores concluíram que os pacientes estariam dispostos a aceitar outras complicações, e mesmos custos pessoais adicionais, para atenuar ou prevenir $\mathrm{NVPO}^{(1)}$.

Além do aspecto subjetivo do desconforto, os pacientes que não apresentam melhora dos sintomas relacionados à náusea e vômito, podem ter alta retardada, tanto da SRA quanto hospitalar e a necessidade de internação após procedimentos ambulatoriais. Como conseqüências, temos a demora do retorno às funções normais, a elevação dos custos hospitalares e a insatisfação do paciente. Aliados a esses fatores, existem as potenciais conseqüências orgânicas, como taquicardia, hipertensão, interrupção da alimentação oral, desidratação, aumento da pressão intracraniana e ocular, sangramento da ferida operatória por aumento da pressão venosa e deiscência das linhas de sutura ${ }^{(2)}$. Também ocorre aumento das chances de aspiração pulmonar, principalmente, em pacientes cujos reflexos da via aérea ainda estão parcialmente deprimidos por anestésicos residuais.

A incidência de náusea e vômito no período pósoperatório apresenta variações extremas, provavelmente em função de uma etiologia multifatorial, na qual várias causas interagem a partir do pré-operatório até o ato anestésicocirúrgico. Atualmente, apesar dos avanços das técnicas anestésicas, do uso de fármacos de curta duração de ação, e do desenvolvimento de novos antieméticos, a incidência global permanece cerca de $25 \%$ a $30 \%{ }^{(2-3)}$.

Os termos náusea e vômito são freqüentemente utilizados juntos, embora cada fenômeno possa ser avaliado separadamente, uma vez que algumas intervenções são mais eficazes contra náuseas e outras contra vômitos. Náusea é definida como uma sensação desagradável associada à vontade de vomitar, acompanhada de palidez ou rubor, taquicardia e impulso do vômito ${ }^{(2)}$. Vômito ou emese é caracterizado pela contração da musculatura abdominal, abaixamento do diafragma, relaxamento da cárdia gástrica, resultando em expulsão do conteúdo do estômago em direção à boca ${ }^{(2)}$. Náusea e vômito no pós-operatório são definidos como um episódio de náusea ou vômito que ocorre nas 24 horas após o recebimento de anestesia.
O processo de náusea e vômito é coordenado pelo centro do vômito, localizado no sistema nervoso central, na medula, próximo do núcleo trato solitário e área posterior do cérebro. A estimulação do centro do vômito pode se dar pelo nervo aferente vagal (exemplo: manipulação dos olhos, orofaringe, trato gastrintestinal), pelo córtex cerebral (exemplo: emoções, visão, olfato), aparelho vestibular (exemplo: cirurgias do ouvido médio), ativação da zona quimiorreceptora do gatilho (ZQG) (exemplo: agentes anestésicos e inalatórios) e o ambiente endócrino (exemplo: gênero feminino) ${ }^{(2)}$.

O controle da náusea e do vômito deve ser uma preocupação do enfermeiro atuante na SRA, podendo ser de modo independente e/ou colaborativo. Observamos na prática clínica que a atuação do profissional diante do controle destas complicações, ainda muito comuns, restringese, na maioria das vezes, ao modo colaborativo, administrando antieméticos quando prescritos e às intervenções relacionadas à prevenção de aspiração do conteúdo gástrico, tais como elevar a cabeceira do leito de $30^{\circ}$ a $45^{\circ}$ graus (se não contra-indicado) e lateralizar a cabeça do paciente; e as relacionadas à avaliação e registro da ocorrência de vômito.

Motivadas por essas considerações, este estudo teve por objetivo avaliar as evidências disponíveis na literatura sobre as intervenções de enfermagem eficazes para a prevenção e o controle da náusea e do vômito presentes no paciente no período pós-operatório imediato, para assim obter informações relevantes que contribuirão para a prática clínica em SRA.

\section{MÉTODOS}

A questão norteadora da presente revisão de literatura consistiu em: "Quais são as intervenções de enfermagem eficazes para a prevenção e o controle da náusea e do vômito freqüentemente presentes no paciente no período pósoperatório imediato?".

No desenvolvimento deste estudo optou-se como fonte de levantamento três bases de dados, descritas a seguir: Literatura Latino-Americana e do Caribe em Ciências da Saúde (LILACS), Cumulattive Index to Nursing and Allied Health Literature (CINAHL) e Medical Literature Analysis and Retrieval Sistem on-line (MEDLINE).

Os critérios de inclusão estabelecidos para os artigos selecionados na presente revisão foram: artigos na íntegra que abordam as intervenções de enfermagem para náusea e vômito no período pós-operatório; provenientes de periódicos indexados nas bases de dados mencionadas, no período de 01/01/1996 a 31/05/2006, realizados em seres humanos, maiores de 18 anos e publicados em português, inglês ou espanhol. Determinou-se como critério de exclusão os artigos cujo enfoque estava pautado somente nas intervenções farmacológicas para náusea e vômito no 
período pós-operatório imediato.

Para a busca dos artigos na base de dados LILACS utilizou-se as seguintes palavras-chave: 1) náusea e vômito pós-operatório e cuidados de enfermagem, não sendo encontrado nenhum estudo. $\mathrm{Na}$ base de dados MEDLINE empregou-se as palavras-chave: 1) postoperative nausea and vomiting and nursing care, na qual foram encontrados 15 estudos. $\mathrm{Na}$ base de dados CINAHL foram utilizadas as seguintes palavras-chave: 1) nausea and vomiting and postoperative period, sendo encontrados 23 artigos. Após a leitura dos resumos e a aplicação dos critérios de inclusão e exclusão, selecionou-se 7 estudos, sendo 4 no CINAHL e 3 no MEDLINE; entretanto, um estudo repetiu-se nas duas bases de dados. Assim, a busca nas bases de dados selecionadas permitiu a inclusão e a análise de 6 artigos.

Utilizamos, ainda, como método para buscar os artigos relevantes da temática investigada, a listagem das referências bibliográficas dos estudos selecionados nas bases de dados mencionadas. Nesta busca, encontramos 6 estudos que estavam de acordo com os critérios de inclusão e exclusão, totalizando 12 artigos que foram incluídos na presente revisão de literatura.

Para a extração dos dados dos artigos incluídos nesta revisão utilizamos o instrumento proposto por $\mathrm{Ursi}^{(4)}$. A análise do delineamento de pesquisa dos artigos foi fundamentada nos conceitos descritos por Polit et al. ${ }^{(5)}$ e o nível de evidências foi definido de acordo com a classificação de Stetler et al. ${ }^{(6)}$.

\section{RESULTADOS}

Dos 12 artigos avaliados, três foram publicados em 2002, dois em 1999, dois em 2000, um em 2003, um em 2004, um em 2005, um em 1997 e um em 1996, apontando um interesse crescente por essa temática, visto que a maioria dos artigos foi publicada nos últimos cinco anos. Observou-se, também, que a totalidade dos artigos foi publicada na literatura internacional, o que evidencia a necessidade de futuras pesquisas abordando essa temática, principalmente no Brasil. Destaca-se, ainda, a importância da base de dados Cinahl, na qual quatro artigos foram selecionados, visto que ainda é pouco utilizada por enfermeiros brasileiros.

Em relação ao tipo de revista em que os artigos foram publicados, há uma maior predominância nas revistas de enfermagem (10 artigos), sendo quatro no Journal of PeriAnesthesia Nursing, três no Journal of Advanced Nursing, um na Nursing Research, um na Applied Nursing Research, e 1 na Orthopaedic Nursing. Dois artigos foram publicados em periódicos médicos, cuja especialidade é a anestesiologia.

Analisamos o delineamento das pesquisas incluídas na revisão, e encontramos que um estudo era de revisão sistemática, sete ensaios clínicos randomizados controlados, um estudo com delineamneto quase-experimental, um descritivo e dois artigos eram revisões de literatura.
Apresenta-se nos Quadros 1, 2, 3 e 4 a síntese dos artigos incluídos na revisão de literatura (Apêndice 1).

\section{DISCUSSÃO}

As intervenções não farmacológicas e alternativas para NVPO têm sido descritas na literatura e podem suplementar ou substituir as intervenções farmacológicas. São elas: o uso do suplemento de oxigênio, do óleo de hortelã, do gengibre, inalação de álcool isopropílico e acupressão.

$\mathrm{O}$ uso do suplemento de $\mathrm{O}_{2}$ na prevenção e tratamento de NVPO foi abordado em dois estudos, sendo considerado eficaz apenas em um, o que demonstra a necessidade de novas pesquisas, abordando a quantidade e tempo de $\mathrm{O}_{2}$ a ser administrado. $\mathrm{O}$ mecanismo no qual o suplemento de $\mathrm{O}_{2}$ interfere na NVPO permanece desconhecido, mas é hipoteticamente sabido que minimiza a hipóxia regional intestinal ${ }^{(7-8)}$.

O óleo de hortelã, usado como aromaterapia, tem sido estudado como tratamento para náuseas, dispepsia e outras complicações gastrintestinais. Nos estudos analisados ${ }^{(9-10)}$ encontramos que há algumas evidências de que o óleo de hortelã pode melhorar as NVPO, além de ser uma alternativa de tratamento com custo menor. No entanto, são necessárias futuras pesquisas, com amostras mais representativas, confirmando ou não a eficácia desta intervenção.

O gengibre é um remédio antiemético botânico mencionado para alívio das NVPO, porém as evidências disponíveis ainda são restritas para recomendar esta modalidade de tratamento na prática clínica. Há necessidade de novas pesquisas abordando o gengibre para o gerenciamento de $\mathrm{NVPO}^{(11)}$.

A inalação do álcool isopropílico, atuante na regulação dos neurotransmissores envolvidos no reflexo emético, foi recomendada em dois artigos incluídos nessa revisão. $\mathrm{O}$ estudo, cuja metodologia utilizada foi o ensaio clínico randomizado controlado, concluiu que o álcool isopropílico apresentou vantagem na diminuição das NVPO porque seu odor foi prontamente detectado pelos pacientes, o que fez estes pensarem que o sintoma seria tratado com a inalação do vapor do álcool, induzindo assim o exercício respiratório ${ }^{(11)}$. Então, verificou-se a necessidade de novas pesquisas experimentais que abordem a duração do efeito, dose necessária, outros métodos de inalação e fatores que podem afetar a efetividade da inalação deste produto, antes de ser utilizado na prática clínica ${ }^{(10,12)}$.

A acupressão segue os mesmos princípios da acupuntura (tradicional forma da medicina chinesa que utiliza pequenas punções na pele em pontos específicos para a transferência de energia), mas substitui a agulha por pressão com os dedos. Dois pontos são utilizados para prevenir NVPO, a saber: Neiguan (P6), localizado dois dedos acima do pulso, entre os ossos rádio e ulna e Shenmem $(\mathrm{H} 7)$, situado entre os ossos do pulso e ulna ${ }^{(13-15)}$. Comercialmente, encontra-se 
disponível bandagem de pulso, a qual fornece pressão desses pontos, no entanto é necessário consulta a um especialista da área para fornecer dados corretos para executar tal procedimento.

A acupressão, embora eficaz no controle de NVPO, exige conhecimentos específicos sobre os fenômenos que o cercam, sendo necessária a presença de um médico acupunturista para a realização desta intervenção. Acreditamos que a maioria dos hospitais brasileiros, se não todos, não dispõem de um profissional especialista nessa área na SRA, o que impede a atuação do enfermeiro na realização desta intervenção, mesmo que de modo colaborativo.

Algumas alternativas foram identificadas para o tratamento de NVPO nos artigos analisados, a saber: movimentar o paciente de maneira suave e lenta, controlar a dor (evitar agentes opióides, dando preferência aos antiinflamatórios não esteroidais e anestésicos locais), evitar a hipotensão, colocar toalhas frescas sobre a testa, aumentar fluídos intravenosos, encorajar respiração profunda e lenta, evitar máscara de $\mathrm{O}_{2}$ apertada, realizar técnicas de distração e relaxamento, imagem dirigida, toque terapêutico e evitar o contato com certos odores, tais como de perfumes, vômitos e medicações ${ }^{(2,16-17)}$.

Dentre estes estudos, um abordou a importância da atuação da enfermagem na avaliação e no registro do episódio de náusea na ficha de avaliação do paciente, demonstrando que esta atividade ainda é deficiente por parte dos enfermeiros, evidenciando a necessidade de construção de diretrizes clínicas para o gerenciamento de náuseas no período pós-operatório ${ }^{(17)}$.

\section{CONCLUSÃO}

Conclui-se que o tema investigado ainda apresenta lacunas, sendo necessário futuras pesquisas confirmando ou não a eficácia da hortelã, do gengibre, do álcool isopropílico e do suplemento de oxigênio como métodos de prevenção e controle de NVPO.

A acupressão é considerada eficaz no controle de NVPO, porém a enfermagem ainda não apresenta habilidades para exercer tal procedimento. De acordo com a portaria no 971 do Ministério da Saúde, publicada no dia 3 de maio de 2006, os profissionais da saúde poderão exercer a acupuntura, desde que capacitados através de cursos de graduação ou pós-graduação, podendo ser possível, em breve, a realização da acupressão pelos enfermeiros.

De acordo com o objetivo do estudo, entendemos que as intervenções de enfermagem para náusea e vômito no período pós-operatório incluem a avaliação do paciente nos três períodos da experiência cirúrgica, ou seja, pré, trans e pós-operatório, tendo como principal ferramenta o processo de enfermagem.

No pré-operatório o enfermeiro identifica os fatores de risco e minimiza a ansiedade; no trans-operatório atua, na maioria das vezes, de maneira colaborativa, atentando-se aos fatores que podem levar o paciente a apresentar NVPO.

No período pós-operatório imediato, foco do estudo, considerou-se as seguintes intervenções de enfermagem independentes: movimentar o paciente lentamente, evitando movimentos bruscos; controlar a dor; encorajar respiração profunda e lenta; evitar a hipotensão; evitar máscara de oxigênio apertada; controlar os fatores ambientais capazes de provocar a náusea, como certos odores, sons e estimulação visual desagradável; colocar toalhas frescas sobre a testa; realizar técnicas de distração e relaxamento; imagem dirigida; registrar episódio de náusea e vômito na ficha de avaliação do paciente.

Acreditamos que seja necessário o enfermeiro estar alicerçado em conhecimento científico para implementar intervenções eficazes contra NVPO e fornecer um cuidado individualizado e de qualidade ao paciente cirúrgico.

\section{REFERÊNCIAS}

1. EberhartLH,Morin AM, Wulf $\mathrm{H}$, GeldnerG. Patient preferences for immediate postoperative recovery. BrJ Anaesth. 2002;89(5):760-1.

2. Golembiewski JA, O'Brien D. A systematic approach to the management of postoperative nausea and vomiting. J Perianesth Nurs. 2002;17(6):364-76.

3. Deane-Valentine Y. An audit of nausea and vomiting in a Post Anaesthetic Care Unit. Br J Anaesthetic Recovery Nurs. 2005; 6(1):4-6.

4. Ursi ES. Prevenção de lesões de pele no perioperatório: revisão integrativa da literatura [tese]. Ribeirão Preto: Escola de Enfermagem de Ribeirão Preto da Universidade de São Paulo; 2005.

5. Polit DF, Bech CT, Hungler BP. Fundamentos de pesquisa em enfermagem: métodos, avaliação e utilização. $5 \mathrm{a}$ ed. Porto Alegre: Artmed; 2004.

6. Stetler CB, Morsi D, Rucki S, Broughton S, Corrigan B, Fitzgerald J, et al. Utilization-focused integrative reviews in nursing service. Appl Nurs Res. 1998; 11(4): 195-206.

7. Ghods AA, Soleimani M., Narimani M. Effect of postoperative supplemental oxygen on nausea and vomiting after cesarean birth. J Perianesth Nurs. 2005; 20(3):200-5.

8. Greif R, Laciny S, Rapf B, Hickle RS, Sessler DI. Supplemental oxygen reduces the incidence of postoperative nausea and vomiting. Anesthesiology. 1999; 91(5):1246-52.

9. Tate S. Peppermint oil: a treatment for postoperative nausea. J Adv Nurs. 1997; 26(3):543-9.

10. Anderson LA, Gross JB. Aromatherapy with peppermint, isopropyl alcohol, or placebo is equally effective in relieving postoperative nausea. J Perianesth Nurs. 2004; 19(1): 29-35.

11. Ernst E, Pittler MH. Efficacy of ginger for nausea and vomiting: a systematic review of randomized clinical trials. $\mathrm{Br}$ J Anaesth. 2000; 84(3):367-71. Review.

12. Merrit BA, Okyere CP, Jasinski DM. Isopropyl alcohol inhalation: alternative treatment of postoperative nausea and vomiting. Nurs Res. 2002; 51(2):125-8.

13. MingJL, Kuo BI, Lin JG, Lin LC. The efficacy of acupressure to prevent nausea and vomiting in post-operative patients. J Adv Nurs. 2002; 39(4):343-51.

14. Schultz AA, Andrews AL, Goran SF, Mathew T, Sturdevant $\mathrm{N}$. Comparison of acupressure bands and droperidol for reducing post-operative nausea and vomiting in gynecologic surgery patients. Appl Nurs Res. 2003; 16(4):256-65. 
15. Ferrara-Love R, Sekeres L, Bircher NG. Nonpharmacologic treatment of postoperative nausea. J Perianesth Nurs. 1996; 11(6):378-83.

16. Gunta K, Lewis C, Nuccio S. Prevention and management of postoperative nausea and vomiting. Orthop Nurs. 2000; 19(2):39-48.

17. Thompson HJ. The management of post-operative nausea and vomiting. J Adv Nurs. 1999; 29(5):1130-6. Review.

\section{APÊNDICE 1}

Qaudro 1 - Síntese dos artigos sobre o uso de suplemento de oxigênio para NVPO.

\begin{tabular}{|c|c|c|c|c|}
\hline Artigo & $\begin{array}{l}\text { Delineamento do } \\
\text { estudo/ Amostra/ } \\
\text { nível de evidência }\end{array}$ & Intervenção estudada & Resultados & Conclusões/Recomendações \\
\hline $\begin{array}{c}\text { Ghods et } \\
\text { al. }(7) \text {. }\end{array}$ & $\begin{array}{l}\text { Ensaio clínico } \\
\text { randomizado } \\
\text { controlado. } \\
\\
\mathrm{n}=106 \\
\mathrm{CE}=53 \\
\mathrm{GC}=53 \\
\text { Nível de } \\
\text { evidência: } 2\end{array}$ & $\begin{array}{l}\text { Testar se o suplemento de } \mathrm{O}_{2} \text { é } \\
\text { eficaz na redução da incidência } \\
\text { de } \mathrm{NVPO} \text { após cesariana (grupo } \\
\text { experimental recebeu } \mathrm{O}_{2} \text { a } 8 \mathrm{l} / \mathrm{min} \text { e } \\
\text { grupo controle recebeu } \mathrm{O}_{2} \text { a } 51 / \mathrm{min} \text {, } \\
\text { ambos através de máscara facial por } \\
\text { um período de } 6 \text { horas). }\end{array}$ & $\begin{array}{c}\text { A incidência de NVPO nas } \\
\text { primeiras } 6 \text { horas foi de } \\
28,3 \% \text { no grupo } \\
\text { experimental e de } 24,5 \% \\
\text { no grupo controle, não } \\
\text { ocorrendo diferença } \\
\text { estatisticamente } \\
\text { significante entre os dois } \\
\text { grupos }\end{array}$ & $\begin{array}{c}\text { O estudo apontou que o } \\
\text { suplemento de } \mathrm{O}_{2} \text { a } 81 / \text { min não } \\
\text { reduz a incidência de NVPO em } \\
\text { pacientes submetidas à } \\
\text { cesariana. } \\
\text { Os autores sugeriram novas } \\
\text { pesquisas com amostras mais } \\
\text { representativas para determinar } \\
\text { o efeito do suplemento de } \mathrm{O}_{2} \\
\text { nas NVPO. }\end{array}$ \\
\hline Greif et al.(8) & $\begin{array}{c}\text { Ensaio clínico } \\
\text { randomizado } \\
\text { controlado. } \\
\\
\mathrm{n}=231 \\
\mathrm{GE}=112 \\
\mathrm{GC}=119 \\
\text { Nível de } \\
\text { evidência: } 2 \\
\end{array}$ & $\begin{array}{c}\text { Testar a hipótese de que a } \\
\text { administração de } \mathrm{O}_{2} \text { suplementar } \\
\text { no perioperatório reduz a } \\
\text { incidência de NVPO. } \\
\text { O grupo experimental recebeu } \\
\mathrm{O}_{2} \text { a } 80 \% \text { e o grupo controle } \mathrm{O}_{2} \\
\text { a } 30 \% \text {. }\end{array}$ & $\begin{array}{c}\mathrm{O} \text { estudo mostrou que o } \\
\mathrm{O}_{2} \text { quando administrado } \\
\text { durante e por } 2 \text { horas após } \\
\text { a cirurgia reduz a } \\
\text { incidência de NVPO. A } \\
\text { incidência de NVPO no } \\
\text { grupo experimental foi de } \\
17 \% \text { enquanto que no } \\
\text { grupo controle foi de } 30 \% \text {. }\end{array}$ & $\begin{array}{l}\text { Os autores concluíram que o } \\
\text { suplemento de } \mathrm{O}_{2} \text { pode ser um } \\
\text { efetivo método na redução de } \\
\text { NVPO em pacientes } \\
\text { submetidos à cirurgia de } \\
\text { ressecção de cólon. }\end{array}$ \\
\hline
\end{tabular}


Quadro 2 - Síntese dos artigos sobre hortelã, gengibre e álcool isopropílico para NVPO.

\begin{tabular}{|c|c|c|c|c|}
\hline Artigo & $\begin{array}{l}\text { Delineamento do } \\
\text { estudo/ Amostra/ } \\
\text { nível de evidência }\end{array}$ & Intervenção estudada & Resultados & Conclusões/Recomendações \\
\hline Tate( $(9)$ & $\begin{array}{c}\text { Ensaio clínico } \\
\text { randomizado } \\
\text { controlado } \\
\mathrm{n}=18 \\
\mathrm{GC}=6 \\
\mathrm{GE}=6 \\
\mathrm{GP}=6 \\
\text { Nível de evidência: } 2\end{array}$ & $\begin{array}{c}\text { Testar a eficácia da } \\
\text { inalação do óleo de hortelã } \\
\text { como tratamento para } \\
\text { NVPO. O grupo } \\
\text { experimental recebeu óleo } \\
\text { de hortelã, o grupo } \\
\text { controle não recebeu } \\
\text { tratamento e o placebo } \\
\text { essência de hortelã. } \\
\end{array}$ & $\begin{array}{l}\text { O grupo experimental } \\
\text { reportou menos náusea e } \\
\text { administrou-se menor } \\
\text { dosagem de agentes } \\
\text { antieméticos do que os } \\
\text { outros dois grupos. }\end{array}$ & $\begin{array}{l}\text { Os autores concluíram que há } \\
\text { algumas evidências que sugerem } \\
\text { que a inalação do óleo de hortelã } \\
\text { pode melhorar as NVPO em } \\
\text { pacientes ginecológicas. }\end{array}$ \\
\hline $\begin{array}{c}\text { Ernst \& } \\
\text { Pittler(11). }\end{array}$ & $\begin{array}{c}\text { Revisão } \\
\text { Sistemática. } \\
\mathrm{n}=6 \\
\text { Nível de evidência: } 1\end{array}$ & $\begin{array}{l}\text { Avaliar e eficácia do } \\
\text { gengibre no gereciamento } \\
\text { de NVPO, por meio de } \\
\text { ensaios clínicos } \\
\text { randomizados. }\end{array}$ & $\begin{array}{l}\text { Dos } 6 \text { artigos analisados, } 3 \\
\text { eram de náusea e vômito } \\
\text { no período pós-operatório } \\
\text { e dois destes sugeriram que } \\
\text { o gengibre foi superior ao } \\
\text { placebo e igualmente } \\
\text { efetivo a metoclopramida. } \\
\text { Os demais estudos } \\
\text { enfocaram náuseas } \\
\text { relacionada a gravidez e } \\
\text { quimioterapia }\end{array}$ & $\begin{array}{l}\text { A síntese do conhecimento } \\
\text { demonstrou que o gengibre é um } \\
\text { promissor remédio botânico, } \\
\text { mas os dados clínicos são } \\
\text { insuficientes para confirmar sua } \\
\text { efetividade. Os autores } \\
\text { apontaram a necessidade de } \\
\text { novos estudos. }\end{array}$ \\
\hline $\begin{array}{c}\text { Anderson \& } \\
\text { Gross }^{(10)}\end{array}$ & $\begin{array}{l}\text { Ensaio clínico } \\
\text { randomizado e } \\
\text { controlado; } \\
\text { n }=33 \\
\text { GE1 }=11 \\
\text { GE2 }=10 \\
\text { GC }=12 \\
\text { Nível de evidência: } 2\end{array}$ & $\begin{array}{l}\text { Determinar se a aromaterapia } \\
\text { com álcool isopropilico e óleo } \\
\text { de hortelã são efetivos no } \\
\text { tratamento de pacientes que } \\
\text { desenvolvem náusea após } \\
\text { cirurgias. Os pacientes foram } \\
\text { randomizados em } 3 \text { grupos: } \\
\text { um recebendo inalação de } \\
\text { álcool isopropilico, outro } \\
\text { inalando hortelã e o grupo } \\
\text { placebo recebendo solução } \\
\text { salina. }\end{array}$ & $\begin{array}{l}\text { Houve redução nos } \\
\text { escores de náusea após a } \\
\text { aromaterapia nos três } \\
\text { grupos; entretanto, não } \\
\text { ocorreu diferença } \\
\text { estatisticamente } \\
\text { significante entre eles. Os } \\
\text { autores apontaram que o } \\
\text { efeito benéfico dos três } \\
\text { tratamentos pode estar } \\
\text { relacionado ao padrão } \\
\text { respiratório e não ao } \\
\text { aroma inalado. }\end{array}$ & $\begin{array}{l}\text { Os autores concluem que a } \\
\text { aromaterapia deve ser } \\
\text { considerada como tratamento } \\
\text { inicial para náusea na SRA } \\
\text { devido a sua efetividade, baixo } \\
\text { custo, facilidade de acesso, } \\
\text { conhecimento pelos pacientes e } \\
\text { ausência de efeitos colaterais } \\
\text { conhecidos. No entanto, há } \\
\text { necessidade de novas pesquisas } \\
\text { com amostras mais } \\
\text { representativas e outros estudos } \\
\text { que verifiquem se a hipótese do } \\
\text { padrão respiratório eficaz para o } \\
\text { tratamento de NVPO está } \\
\text { correta. }\end{array}$ \\
\hline Merrit et al.(12) & $\begin{array}{c}\begin{array}{c}\text { Estudo quase- } \\
\text { experimental }\end{array} \\
\qquad \begin{array}{c}\mathrm{n}=39 \\
\mathrm{CE}=21 \\
\mathrm{GC}=18 \\
\text { Nível de evidência: } 3\end{array}\end{array}$ & $\begin{array}{l}\text { Avaliar a efetividade da } \\
\text { inalação do álcool } \\
\text { isopropílico (IAI) para o } \\
\text { tratamento de NVPO. O } \\
\text { grupo experimental } \\
\text { recebeu a IAI e o grupo } \\
\text { controle medicação } \\
\text { antiemética padronizada na } \\
\text { instituição. }\end{array}$ & $\begin{array}{l}\text { Não houve diferença } \\
\text { estatisticamente } \\
\text { significante entre o } \\
\text { tratamento padrão com } \\
\text { antieméticos e o } \\
\text { tratamento com IAI. }\end{array}$ & $\begin{array}{l}\text { Os autores concluíram que a IAI } \\
\text { é efetiva e apresenta menor } \\
\text { chance de efeitos colaterais que } \\
\text { as drogas antieméticas; } \\
\text { entretanto, novas pesquisas são } \\
\text { necessárias a fim de avaliar a } \\
\text { extensão da efetividade, as doses } \\
\text { necessárias, outras maneiras de } \\
\text { inalação e fatores que impedem a } \\
\text { efetividade da IAI. }\end{array}$ \\
\hline
\end{tabular}


Quadro 3 - Síntese dos artigos sobre acupressão para NVPO.

\begin{tabular}{|c|c|c|c|c|}
\hline Artigo & $\begin{array}{l}\text { Delineamento do } \\
\text { estudo/ Amostra/ } \\
\text { nível de evidência }\end{array}$ & Intervenção estudada & Resultados & Conclusões/Recomendações \\
\hline Ming et al.(13) & $\begin{array}{c}\text { Ensaio clínico } \\
\text { randomizado } \\
\text { controlado. } \\
\mathrm{n}=150 \\
\mathrm{GE}_{1}=50 \\
\mathrm{GE}_{2}=50 \\
\mathrm{GC}=50 \\
\text { Nível de } \\
\text { evidência: } 2\end{array}$ & $\begin{array}{l}\text { Examinar o efeito da } \\
\text { estimulação de dois pontos } \\
\text { de acupressão na prevenção } \\
\text { de NVPO. O primeiro } \\
\text { grupo de pacientes recebeu } \\
\text { acupressão através dos } \\
\text { dedos; o segundo através de } \\
\text { bandagens de pulso e o } \\
\text { terceiro, grupo controle, } \\
\text { não recebeu estimulação. }\end{array}$ & $\begin{array}{l}\text { O primeiro grupo teve } \\
\text { redução da incidência } \\
\text { de náusea }(73 \%) \text { e } \\
\text { vômito }(90 \%) \text { em } \\
\text { relação ao grupo } \\
\text { controle. O segundo } \\
\text { grupo teve uma } \\
\text { redução de } 43 \% \text { de } \\
\text { náusea e } 42 \% \text { de } \\
\text { vômito em relação ao } \\
\text { grupo controle. }\end{array}$ & $\begin{array}{l}\text { Os autores indicaram o uso da } \\
\text { acupressão como opção de } \\
\text { tratamento para NVPO, } \\
\text { considerando-se os resultados } \\
\text { deste estudo, como também a } \\
\text { ausência de efeitos colaterais da } \\
\text { acupressão. }\end{array}$ \\
\hline Schultz et al.(14). & $\begin{array}{c}\text { Ensaio clínico } \\
\text { randomizado } \\
\text { controlado. } \\
\mathrm{n}=103 \\
\mathrm{GE}_{1}=30 \\
\mathrm{GE}_{2}=24 \\
\mathrm{GE}_{3}=24 \\
\mathrm{GC}=25 \\
\text { Nível de } \\
\text { evidência: } 2\end{array}$ & $\begin{array}{l}\text { Avaliar a efetividade da } \\
\text { acupressão por bandagem e } \\
\text { droperidol na redução das } \\
\text { NVPO. Os pacientes foram } \\
\text { randomizados em } 4 \text { grupos: } \\
\text { 1) droperidol e acupressão; } \\
\text { 2) droperidol e } \\
\text { acupressão/placebo; 3) } \\
\text { droperidol/ placebo e } \\
\text { acupressão e 4) placebo e } \\
\text { placebo. }\end{array}$ & $\begin{array}{l}\text { O grupo } 2 \\
\text { experimentou menos } \\
\text { náusea que os outros } \\
\text { três grupos. No } \\
\text { entanto, em relação ao } \\
\text { vômito o estudo não } \\
\text { mostrou diferença } \\
\text { estatisticamente } \\
\text { significante entre os } \\
\text { quatro grupos. }\end{array}$ & $\begin{array}{l}\text { Os autores encontraram que, } \\
\text { embora o droperidol tenha sido } \\
\text { mais efetivo no dia da cirurgia, a } \\
\text { acupressão por bandagem e a } \\
\text { droga droperidol não foram } \\
\text { efetivas na redução das NVPO } \\
\text { nas pacientes submetidas à } \\
\text { cirurgia ginecológica, tanto na } \\
\text { modalidade singular quanto } \\
\text { combinada. }\end{array}$ \\
\hline Ferrara-Love et al.(15) & $\begin{array}{l}\text { Ensaio clínico } \\
\text { randomizado } \\
\text { controlado } \\
\mathrm{n}=90 \\
\mathrm{GE}=30 \\
\mathrm{GP}=30 \\
\mathrm{GC}=30 \\
\text { Nível de } \\
\text { evidência: } 2\end{array}$ & $\begin{array}{l}\text { Testar o efeito da } \\
\text { acupressão na incidência de } \\
\text { NVPO. O grupo } \\
\text { experimental usou } \\
\text { bandagens elásticas } \\
\text { bilaterais nos pulsos; o } \\
\text { placebo bandagens elásticas } \\
\text { incapazes de exercer } \\
\text { pressão nos pontos e o } \\
\text { grupo controle recebeu } \\
\text { rotinas médicas e de } \\
\text { enfermagem. }\end{array}$ & $\begin{array}{l}\text { A incidência de náusea } \\
\text { diminuiu nos grupos } \\
\text { experimental e placebo, } \\
\text { quando comparado ao } \\
\text { grupo controle. }\end{array}$ & $\begin{array}{l}\text { A utilização da acupressão através } \\
\text { de bandagens reduz a incidência } \\
\text { de náusea quando comparado ao } \\
\text { grupo controle. Os autores } \\
\text { concluíram que esse tipo de } \\
\text { intervenção não farmacológica } \\
\text { pode ser uma efetiva opção de } \\
\text { tratamento para náusea no PO. } \\
\text { No entanto sugeriram outros } \\
\text { estudos, com amostras mais } \\
\text { representativas. }\end{array}$ \\
\hline
\end{tabular}


Quadro 4 - Síntese dos artigos sobre cuidados farmacológicos e não farmacológicos para NVPO.

\begin{tabular}{|c|c|c|c|c|}
\hline Artigo & $\begin{array}{l}\text { Delineamento do } \\
\text { estudo/ Amostra/ } \\
\text { nível de evidência }\end{array}$ & Intervenção estudada & Resultados & Conclusões/Recomendações \\
\hline Gunta et al. ${ }^{(16)}$ & $\begin{array}{l}\text { Estudo descritivo } \\
\qquad \mathrm{n}=298 \\
\text { Nível de evidência: } 4\end{array}$ & $\begin{array}{l}\text { Identificar a efetividade das } \\
\text { ações de enfermagem } \\
\text { independentes e } \\
\text { interdependentes para } \\
\text { prevenção e gerenciamento } \\
\text { de NVPO. }\end{array}$ & $\begin{array}{l}\text { As medidas de conforto, } \\
\text { o aumento dos fluídos } \\
\text { endovenosos e o } \\
\text { encorajamento da } \\
\text { respiração profunda e } \\
\text { lenta foram as ações mais } \\
\text { freqüentes } \\
\text { implementadas pela } \\
\text { enfermagem. }\end{array}$ & $\begin{array}{l}\text { Os autores apontaram a necessidade } \\
\text { de educação dos enfermeiros em } \\
\text { relação a fisiologia, incidência, } \\
\text { fatores predisponentes e opções de } \\
\text { tratamento para NVPO, uma vez que } \\
\text { o estudo mostrou que a avaliação } \\
\text { das NVPO são inconsistentes e os } \\
\text { resultados das intervenções não são } \\
\text { avaliados. Os autores sugeriram a } \\
\text { construção de um protocolo de } \\
\text { cuidado que forneça uma rotina de } \\
\text { intervenções para essa complicação } \\
\text { pós-operatória. }\end{array}$ \\
\hline $\begin{array}{c}\text { Golembiewski \& } \\
\text { Brien }^{(2)}\end{array}$ & Revisão de Literatura & $\begin{array}{l}\text { Apresentar um algoritmo } \\
\text { baseado em evidências sobre } \\
\text { a prevenção e o tratamento } \\
\text { de NVPO em pacientes } \\
\text { adultos. }\end{array}$ & $\begin{array}{c}\text { No PO foram } \\
\text { consideradas as seguintes } \\
\text { ações: controle da dor, } \\
\text { adequada hidratação e } \\
\text { oxigenação, encorajar } \\
\text { respiração profunda e } \\
\text { lenta, evitar movimentos } \\
\text { bruscos, evitar } \\
\text { hipotensão, considerar } \\
\text { técnicas de acupressão, } \\
\text { inalação de álcool } \\
\text { isopropílico e utilizar } \\
\text { agentes antieméticos. }\end{array}$ & $\begin{array}{l}\text { Os autores concluíram que as drogas } \\
\text { antieméticas são eficazes; entretanto, } \\
\text { oferecem riscos, podendo ser } \\
\text { reservadas aos pacientes que } \\
\text { apresentarem alto risco de NVPO. } \\
\text { Então, sugeriram as ações não } \\
\text { farmacológicas como prioritárias no } \\
\text { gerenciamento das NVPO. }\end{array}$ \\
\hline Thompson $^{(17)}$ & Revisão de literatura. & $\begin{array}{l}\text { Avaliar o mecanismo de } \\
\text { prevenção, tratamento e } \\
\text { controle das NVPO e } \\
\text { desenvolver diretrizes para a } \\
\text { avaliação do paciente } \\
\text { relacionada a essas } \\
\text { complicações }\end{array}$ & $\begin{array}{l}\text { Intervenções eficazes: 1) } \\
\text { no pré-operatório: avaliar } \\
\text { os fatores de risco e } \\
\text { minimizar a ansiedade; 2) } \\
\text { no trans-operatório o } \\
\text { enfermeiro trabalha de } \\
\text { modo colaborativo e 3) } \\
\text { no PO: antieméticos, } \\
\text { técnicas de distração e } \\
\text { relaxamento, toque } \\
\text { terapêutico, acupressão, } \\
\text { encorajar respiração } \\
\text { profunda e lenta, } \\
\text { movimentação suave e } \\
\text { lenta, evitar contato com } \\
\text { certos odores. }\end{array}$ & $\begin{array}{l}\mathrm{O} \text { autor considerou importante um } \\
\text { plano de cuidados ao paciente } \\
\text { cirúrgico que envolva uma avaliação } \\
\text { pré operatória, assim como a } \\
\text { identificação de intervenções } \\
\text { farmacológicas e não farmacológicas } \\
\text { decididas em conjunto com o } \\
\text { paciente, com o objetivo de } \\
\text { promover a prevenção e o } \\
\text { tratamento das NVPO. }\end{array}$ \\
\hline
\end{tabular}

